\title{
Decellularization reduces calcification while improving both durability and 1-year functional results of pulmonary homograft valves in juvenile sheep
}

Richard A. Hopkins, MD, ${ }^{\mathrm{a}, \mathrm{c}}$ Alyce Linthurst Jones, MS, RAC, ${ }^{\mathrm{b}}$ Lloyd Wolfinbarger, PhD, ${ }^{\mathrm{b}}$ Mark A. Moore, PhD, Arthur A. Bert, MD, a,c and Gary K. Lofland, MD

Objective: The juvenile sheep functional valve chronic implant calcification model was used to compare longterm calcification rates, functional performance, and durability for 3 types of right ventricular outflow tract implants: classically cryopreserved homografts and 2 decellularized pulmonary valved conduits.

\begin{abstract}
Methods: Fifteen juvenile sheep were randomly assigned to one of 3 study arms and underwent pulmonary valve replacement. The arms included the following: (1) cryopreserved ovine pulmonary valves; (2) cryopreserved, decellularized, saline $\left(1^{\circ} \mathrm{C}-10^{\circ} \mathrm{C}\right)$-stored ovine pulmonary valves; and (3) cryopreserved, decellularized, glycerolized $\left(-80^{\circ} \mathrm{C}\right)$ stored ovine pulmonary valves. Animal growth, serial echocardiographic results (with valve performance assessment), dimensions, and tissue-specific calcification measurements were compared with preexplant angiographic analysis and right ventricular outflow tract pressure measurements, cardiac magnetic resonance imaging, specimen radiographic analysis, gross explant pathology, and histopathology. Parametric and nonparametric statistical analysis were performed.
\end{abstract}

Results: All but 2 study animals receiving implants thrived postoperatively, with similar growth rates, explant valve dimensions, ventricular functions, cardiac output, and indices during the study. As determined by means of echocardiographic analysis, 3 animals in arm 1 (and one in arm 2) had leaflet dysfunction. Valve regurgitation was recognized in 1 survivor each from both arms 1 and 2. Although 1 arm 1 animal died with calcified subacute bacterial endocarditis, and the other 4 had leaflet and conduit wall calcification by the time of death, no arm 2 or arm 3 animals demonstrated leaflet calcium, and no arm 3 and only 1 arm 2 animals had calcium in the conduit wall over the entire year, as determined with any measurement method. All cryopreserved conduit walls had calcium by 20 weeks, whereas only 1 of 10 decellularized conduits (arms 2 plus 3 ) had wall calcium.

Conclusion: Cryopreserved-decellularized-glycerolized valves retained normal valve function, with absent leaflet and minimal wall calcifications 1 year postoperatively, as opposed to classically cryopreserved allografts. These results might be predictive of the prolonged durability and functionality of a cryopreserved-decellularized-glycerolized allograft valve.

Supplemental material is available online.

Cryopreserved homograft valves retain donor cells with varying degrees of metabolic activity. Cells become apoptotic as a result of harvest, transport, and cryopreservation,

\footnotetext{
From the Cardiac Surgery Research Laboratories, ${ }^{\text {a }}$ The Children's Mercy Hospitals and Clinics, Kansas City, Mo; LifeNet Health, ${ }^{\text {b }}$ Virginia Beach, Va; and Brown University Medical School, ${ }^{\mathrm{c}}$ Providence, RI.

Read at the Thirty-fourth Annual Meeting of the Western Thoracic Surgical Association, Kona, Hawaii, June 25-28, 2008.

Supported by grants from the Children's Heart Foundation and LifeNet Health. Dr Hopkins' research time was supported, in part, by the Collis Family Endowment and the Karl E. and Gloria A. Karlson Endowed Professorial Chair for Cardiac Surgery.

Received for publication June 19, 2008; revisions received Nov 7, 2008; accepted for publication Dec 19, 2008.

Address for reprints: Richard A. Hopkins, MD, Children's Mercy Hospitals and Clinics, 2401 Gillham Rd, Kansas City, MO 64108 (E-mail: rahopkins@cmh.edu). J Thorac Cardiovasc Surg 2009;137:907-13

0022-5223/\$36.00

Copyright (c) 2009 by The American Association for Thoracic Surgery

doi:10.1016/j.jtcvs.2008.12.009
}

rendering the valve essentially acellular 9 to 12 months after implantation. ${ }^{1}$ Retained antigenic, apoptotic, necrotic, donor cells/cellular debris lead to calcification, chronic inflammation, or both, promoting valve failure. ${ }^{2-5}$ Efficiently decellularized, tissue-engineered homografts might prolong durability by reducing recipient inflammation, immune responses, fibrous scarring, and calcification, ultimately decreasing the number of patients requiring reconstructive cardiac surgery. ${ }^{6}$

The juvenile sheep chronic valve implant model is an excellent predictor of the durability and performance of biologic heart valves as affected by calcification. ${ }^{7,8}$ This model was used in this study to compare long-term calcification rates, functional performance, and putative durability between classically cryopreserved allograft valves (arm 1) and cryopreserved-decellularized allograft pulmonary valve conduits preserved by means of 2 different methods. Arm 2 was comprised of decellularized valves stored in saline $\left(4^{\circ} \mathrm{C}\right)$, and arm 3 consisted of decellularized valves stored in glycerol $\left(-80^{\circ} \mathrm{C}\right)$ for at least 2 weeks before implantation. 


\section{Abbreviations and Acronyms \\ ANOVA $=$ analysis of variance \\ $\mathrm{EOA}=$ effective orifice area \\ MRI = magnetic resonance imaging \\ PRA $=$ panel reactive antibody}

\section{MATERIALS AND METHODS \\ Homograft Harvest and Processing}

Donor valves were harvested from sheep of analogous size, age, and weight but from different breeding stock than recipients. All valves were obtained by means of aseptic excision and in a manner similar to tissue harvest procedures. ${ }^{9}$ Warm ischemic time was less than 1 hour. Each heart was placed in Lactated Ringers solution containing antibiotics and shipped to LifeNet Health (Virginia Beach, Va) on wet ice at $1^{\circ} \mathrm{C}$ to $10^{\circ} \mathrm{C}$. Cold ischemic time before processing did not exceed 24 hours.

On receipt, pulmonary valves were dissected and disinfected by using standard clinical methods $\left(4^{\circ} \mathrm{C}\right.$ for $24 \pm 2$ hours with cefoxitin, lincomycin, polymyxin B, and vancomycin antibiotics). Subsequently, valves were incubated in RPMI 1640 containing 10\% dimethyl sulfoxide and $10 \%$ fetal calf serum and cryopreserved at $-1^{\circ} \mathrm{C} / \mathrm{min}$ by using a computer-controlled freezing profile. Valves were then held in vapor-phase liquid nitrogen for at least 48 hours before decellularization. ${ }^{10}$

\section{Decellularization}

Before decellularization, valves were thawed and diluted of cryoprotectant by using a standard clinical protocol. The valve conduits were decellularized by LifeNet Health as in Appendix E1.

\section{Sheep Chronic Implant Model}

The investigational protocol used in this study was approved by the animal care and use committee. The animals received humane care in compliance with the principles stated in the "Guide for the care and use of laboratory animals" (National Institutes of Health publication no. 85-23). Fifteen juvenile, pre-estrus female domestic sheep (Ovis aries) of a Rambouillet, North Country Cheviot, Suffolk breed mix (163 \pm 27.9 days of age; range, 126-202 days of age) with body weights 30 to $40 \mathrm{~kg}$ were selected as recipients. Age distribution for each arm was as follows: arm 1, $151.2 \pm 28.9$ days (range, 126-196 days); arm 2, $149.0 \pm 20.5$ days (range, 128-173 days); and arm 3, $190.4 \pm 10.9$ days (range, 176-202 days). After achievement of general anesthesia through a left thoracotomy and with cardiopulmonary bypass support, the pulmonary valve was excised, and the test valve was sutured into place as an interposition valved conduit. Animals were matured as a herd for 1 year.

\section{Serial Studies}

The following assessments were performed before implantation and 10, 20, 35, and 52 weeks after valve implantation: animal size, echocardiographic analysis, and panel reactive antibody (PRA) analysis. ${ }^{11}$ Other assessments were performed 1 week before death.

Animal growth. Sheep growth was assessed by means of weight and length measurements and then converted to body surface area by using the Haycock formula. ${ }^{12}$

Echocardiographic analysis. Valve performance was evaluated with transthoracic 2-dimensional echocardiographic and Doppler assessments. Images were obtained in unsedated sheep held in the right lateral decubitus position with a $2.5-\mathrm{MHz}$ transducer and a SONOS 1000 platform (Hewlett-Packard, Palo Alto, Calif). Echocardiographic protocols are fully described in Appendix E2.
PRA assay. Blood specimens were collected from the jugular veins of the sheep. The full serum PRA protocol is included in Appendix E3. ${ }^{11}$

\section{Pre-explantation Studies}

One week before death (week 52), each surviving animal underwent cardiac catheterization with right ventricular and pulmonary arterial angiographic analysis. These techniques are included in Appendices E4 and E5, respectively. All animals in arm 3 (and 1 in arm 1) also underwent cardiac magnetic resonance imaging (MRI), as detailed in Appendix E6.

\section{Valve Explant Studies}

Gross examination and measurements. After necropsy, explants were examined macroscopically (with a dissecting microscope) and radiographically (with an OEC 9600; General Electric, Milwaukee, Wis) for calcification and gross abnormalities. Calcium was mapped on a standardized valve diagram, and leaflet morphology, mobility, and configuration were recorded. Conduit dimensions were measured with calipers. The valves were then fixed for histopathology.

Histopathology. Movat's pentachrome, hematoxylin and eosin (Vector Laboratories, Burlingame, Calif), and either Alizarin red S or Von Kossa staining was performed by using standard histologic methods. Immunohistochemistry, confocal microscopy, electron microscopy, and quantitative morphometrics were also performed and will be reported separately.

\section{Statistics}

For all variables, descriptive statistics (means and standard deviations for continuous variables and proportions for categorical variables) were computed. Echocardiographic variables were compared by using single-factor analysis of variance (ANOVA). A general linear regression model was used for repeated measures (eg, multiple time points). Multivariate analyses included Pillai's Trace, Wilks' Lambda, Hotelling's Trace, and Roy's Largest Root. The SPSS version 15.0 for Windows Statistical Package (SPSS, Inc, Chicago, Ill) was used.

\section{RESULTS}

All but 2 study animals receiving implants thrived postoperatively. One arm 1 animal had bacterial endocarditis at 257 days. One arm 2 animal accidently hanged herself on a feed trough on day 299. All arm 3 animals survived the full 52 weeks. The rate of animal growth was similar for all 3 arms (see Figure E1), with significant increases in body surface area over time (ie, growth, $P=.006$ ). The sheep demonstrated no significant differences in growth curve shapes over the study $(P=.145)$.

\section{Echocardiographic Analysis}

Peak and mean pressure gradients, effective orifice area (EOA) and EOA index were not different among arms over the study (see Table E1). Three animals in arm 1 (and 1 in arm 2) had leaflet dysfunction, whereas function remained normal for all arm 3 animals. Any occurrence of leaflet dysfunction in arm 1 valves was associated with leaflet calcification. The arm 2 animal identified with leaflet dysfunction demonstrated wall calcium by means of echocardiographic analysis, angiographic analysis, and explant macro-observations. Overall, 4 of 5 arm 1, 1 of 5 arm 2, and 0 of 5 arm 3 animals had leaflet calcium, wall calcium, or both, as determined by means of echocardiographic 
analysis. Correlating the echocardiographic results with direct observations and specimen radiographs, the 1 arm 2 conduit positive for calcium by means of echocardiographic analysis had the calcium arising from the distal suture line.

Comparing all arms by means of $\chi^{2}$ analysis, leaflet calcium was more often identified at death for arm 1 animals $(P=.032$, Pearson's test $)$ and for arm 1 versus arm 3 animals $(P=.038$, Pearson's test). The Pearson's test detected higher conduit wall calcium frequencies in arm 1 among the arms $(P=.027)$, with a higher difference between arms 1 and $3(P=.010$, Pearson's test). Ventricular function was not different among the arms.

\section{Cardiac Catheterization and Angiographic Analysis}

One-way ANOVA demonstrated no significant interarm differences in cardiac output, index, Gorlin EOA, and Gorlin EOA index measurements obtained by means of catheterization (see Table E2). One-way ANOVA demonstrated intergroup differences in right ventricular systolic, diastolic, and mean pressures. Pulmonary artery systolic, diastolic, and mean pressures also included statistical differences. However, in all of these instances, the absolute values were considered biologically benign. Mean transvalvular and peak gradients remained low for all groups.

Angiographic analysis demonstrated regurgitation in 1 of $4 \operatorname{arm~1,1~of~} 4$ arm 2, and 0 of 5 arm 3 survivors. Anastomotic or conduit wall calcium was visualized in 2 of 4 arm 1,1 of 4 arm 2, and 0 of 5 arm 3 sheep.

\section{Explant Studies}

Directly measured valve dimensions for age were comparable among the 3 arms over the 52 weeks, excluding one outlier in arm 2, which was also the sheep that had leaflet dysfunction (see Table E3).

At necropsy, grafts were graded for leaflet or conduit wall inflammation, inflammatory changes at suture lines, (eg, pannus formation), graft fibrous scarring (sheathing and capsule formation), gross stenosis or dilatation, and visible or palpable presence of calcifications (Tables 1 and 2). By means of $\chi^{2}$ analysis, the arms were not different except for the presence of calcification, for which the cryopreserved valves were significantly more likely to have calcium at each location in the conduits (Table 2; $P=.011$, Pearson's test); graft fibrous scarring (Table 1; arm 1 scarring greater than that of arms 2 and $3 ; P=.027$, Pearson's test); and suture line scarring (Table 1; arm 1 scarring greater than that of arms 2 and 3; $P=.004$, Pearson's test). Thus arm 1 (cryopreserved) valves consistently graded poorly relative to the decellularized groups.

\section{Calcification}

Cryopreserved valves tended to manifest greater calcification over the study period, which is consistent with clinical human experience. For example, by week 52, the functional
TABLE 1. Explant macro-observations other than calcifications

\begin{tabular}{|c|c|c|c|}
\hline Variable & No. & Prob $>\chi^{2}$ & Inferences \\
\hline Graft inflammation & 14 & .108 & $\begin{array}{l}\text { Treatments were } \\
\text { not significantly } \\
\text { different. }\end{array}$ \\
\hline Adventitial inflammation & 14 & .260 & $\begin{array}{l}\text { Treatments were } \\
\text { not significantly } \\
\text { different. }\end{array}$ \\
\hline $\begin{array}{l}\text { Inflammation at suture } \\
\text { lines }\end{array}$ & 14 & .358 & $\begin{array}{l}\text { Treatments were } \\
\text { not significantly } \\
\text { different. }\end{array}$ \\
\hline Graft scarring & 14 & .027 & $\begin{array}{l}\text { Arm } 1 \text { had a higher } \\
\text { incidence of scarring } \\
\text { than arms } 2 \text { and } 3 .\end{array}$ \\
\hline Suture line scarring & 14 & .004 & $\begin{array}{l}\text { Arm } 1 \text { had a higher } \\
\text { incidence of scarring } \\
\text { at suture lines } \\
\text { than arms } 2 \text { and } 3 .\end{array}$ \\
\hline $\begin{array}{l}\text { Leaflet, annulus, } \\
\text { or conduit scarring }\end{array}$ & 14 & .379 & $\begin{array}{l}\text { Individual tests } \\
\text { were run for each } \\
\text { location. For each, } \\
\text { treatments were not } \\
\text { significantly different. }\end{array}$ \\
\hline $\begin{array}{l}\text { Gross stenosis } \\
\text { or dilation }\end{array}$ & 14 & .379 & $\begin{array}{l}\text { Individual tests } \\
\text { were run for each. } \\
\text { Treatments were not } \\
\text { significantly different. }\end{array}$ \\
\hline BE of leaflets & 15 & .343 & $\begin{array}{l}\text { Treatments were } \\
\text { not significantly } \\
\text { different. }\end{array}$ \\
\hline
\end{tabular}

Nonparametric multivariate analyses (Pearson's test) indicated treatments were different at an $\alpha$ value of .05. Contingency $\chi^{2}$ analyses were performed for each variable to determine which categorical variables contributed to the overall significant difference among treatments. $B E$, Bacterial endocarditis.

studies demonstrated that all 4 animals in arm 1 and none in arm 3 had calcium somewhere in the conduit, as determined by means of either or both echocardiographic and angiographic analysis. An additional animal in arm 1 (that had bacterial endocarditis and died) also demonstrated calcification at its last echocardiographic examination (week 10). Assuming that once identified calcium does not diminish over time, all 5 animals in arm 1 had calcifications over the course of the study; direct observation and specimen radiographs correlated well, demonstrating that all cryopreserved conduits had calcifications involving leaflets and conduit wall; and no decellularized allograft leaflets (groups 2 and 3) had calcium by 52 weeks, as assessed by means of all methods.

When echocardiographic analysis identified calcium, explant macro-observations, specimen radiographic analysis, MRI, and angiographic analysis confirmed this result. However, explant macro-observatory and specimen radiographic analysis were more sensitive, identifying calcifications in all 5 conduits in arm 1 (leaflets and wall), but echocardiographic analysis failed to identify 2 of the 5 arm 1 leaflet calcifications. By means of $\chi^{2}$ analyses, arm 1 was consistently more calcified than arms 2 and 3, although arm 2 was not 
TABLE 2. Univariate analysis: Calcium amounts observed by means of specimen radiographic analysis per location and by treatment.

\begin{tabular}{|c|c|c|c|}
\hline Variable & $\chi^{2}$ & Prob $>\chi^{2}$ & $\begin{array}{l}\text { Inferences from } \\
\text { proportions }\end{array}$ \\
\hline Calcium anywhere & 9.100 & .011 & $\begin{array}{l}\text { Arm } 1 \text { had a higher incidence } \\
\text { of calcium present }(4 / 4) \text { than } \\
\text { arms } 2(2 / 5) \text { and } 3(0 / 5) \text {. }\end{array}$ \\
\hline Distal anastomosis & 11.200 & .082 & $\begin{array}{l}\text { Treatments were not significantly } \\
\text { different. }\end{array}$ \\
\hline STJ & 14.000 & .007 & $\begin{array}{l}\text { Arm } 1 \text { had a higher incidence of } \\
\text { STJ calcium }(4 / 4) \text { than arms } 2 \\
(0 / 5) \text { and } 3(0 / 5) \text {. }\end{array}$ \\
\hline Leaflets & 9.545 & .049 & $\begin{array}{l}\text { Arm } 1 \text { had a higher incidence of } \\
\text { leaflet calcium }(4 / 4) \text { than arms } \\
2(0 / 5) \text { and } 3(0 / 5) \text {. }\end{array}$ \\
\hline Annulus & 14.000 & .007 & $\begin{array}{l}\text { Arm } 1 \text { had a higher incidence of } \\
\text { annulus calcium }(4 / 4) \text { than arms } \\
2(0 / 5) \text { and } 3(0 / 5) \text {. }\end{array}$ \\
\hline Proximal suture & 10.700 & .098 & $\begin{array}{l}\text { Treatments were not significantly } \\
\text { different. }\end{array}$ \\
\hline Conduit wall & 11.356 & .078 & $\begin{array}{l}\text { Treatments were not significantly } \\
\text { different. }\end{array}$ \\
\hline
\end{tabular}

Pearson $\chi^{2}$ tests were used to determine whether there were significant differences in calcium location by treatment. Indicated treatments were different at an $\alpha$ value of 05 . Proportions were used to determine which categorical variables contributed to the overall significant difference among treatments. STJ, sinotubular junction.

quite as favorable as arm 3 (Table 2). Arm 2 animals had calcium identified in the conduit wall (associated with the distal suture line) in 1 case, the proximal suture lines in 2 cases, and never in leaflets. By using direct observations, MRI, and radiographic analysis, only 1 animal of arm 3 had calcification, which occurred only at the proximal anastomosis and did not involve the leaflets or conduit wall. It should be noted that although arm 1 conduit wall calcification as a categorical value was only marginally greater when assessed by means of specimen radiographic analysis (Table $2, P=.078$ ), the magnitude of this calcification as an ordinal variable measured by means of direct observation (see Table E4) was significantly worse for arm 1 among the 3 arms $(P=.023,1$-way ANOVA) and for arm 1 versus arm 3 alone $(P=.011,1$-way ANOVA $)$.

\section{MRI}

MRI analyses (performed on all 5 arm 3 and 1 arm 1 sheep) confirmed the findings of echocardiographic analysis and cardiac catheterization for the following: (1) presence or absence of calcification; (2) calcium deposition by location; and (3) valve leaflet function parameters. No calcifications or valve dysfunctions were identified by means of MRI that were missed by the combination of the other assessments (see Table 3).

\section{PRA Assay}

Scatter plots of the results for the ovine PRA assay (for major histocompatibility complex I and II), representing
TABLE 3. Summary of calcium identified by using 5 measurement methods

\begin{tabular}{lccc}
\hline & \multicolumn{3}{c}{$\begin{array}{c}\text { Calcium identified anywhere } \\
\text { (no. of animals per arm) }\end{array}$} \\
\cline { 2 - 4 } Method of analysis & Arm 1* & Arm 2 & Arm 3 \\
\hline Echocardiography & 4 & 1 & 0 \\
Radiography & 4 & 2 & 1 \\
Direct observation & 4 & 2 & 1 \\
Angiography & 4 & 1 & 0 \\
MRI & $1 \dagger$ & ND & 1 \\
\hline
\end{tabular}

$N D$, Not done. *Note that of the 5 arm 1 animals, 1 had bacterial endocarditis and did not survive the full 52 weeks. However, calcification was identified as present in vegetations, and therefore it can be stated that all arm 1 animals had calcification at some point during the course of the study. †Only 1 animal in arm 1 underwent MRI, whereas all 5 animals in arm 3 underwent MRI. The arm 2 calcifications were associated with the suture lines in 2 animals and the conduit wall near the distal suture line in 1 animal but never in leaflets. For arm 3 , the single calcification occurrence was localized to the proximal suture line and not the leaflets. No decellularized leaflets ( $\mathrm{n}=10$, arms 2 and 3) calcified.

mean fluorescent intensity units over time for each arm, are included in Figure E2. No biologically relevant trends could be extracted from these data. Notably, sheep are inherently immunochallenged, with strong bacterial loads constitutively present in their blood and stomachs. None of the animals received antibiotic treatments after implantation (over the course of the year) to suppress baseline inflammatory responsivity.

\section{Histopathology}

Histology indicated that significant recellularization occurred in the conduit walls and the base of leaflets for decellularized (arms 2 and 3 ) valves (Figures 1 and 2). The arm 3 leaflets were also inconsistently recellularized; however, they appeared to stimulate less pannus formation (fibrous sheathing) than was observed in the cryopreserved (arm 1) control valves. The distribution of calcification for arm 3 valves, as monitored by using the other experimental methods (eg, radiographic analysis and MRI), was supported by these histology results.

Immunohistochemistry suggested that the cells involved in recellularization were consistent with a typical myofibroblast phenotype, including the expression of $\alpha$-smooth muscle actin and heat shock protein 47 (Figure 3).

\section{DISCUSSION}

The utility of the juvenile ovine cardiac valve chronic implant model in assessing calcification potential for biologic constructs placed in the circulation is well precedented. $^{7,8,10,13}$ The juvenile sheep chronic implant model was developed by a joint US Food and Drug Administration-National Institutes of Health/National Heart, Lung, and Blood Institute research effort in the late 1970s to establish a reliable animal marker to assess the calcification 


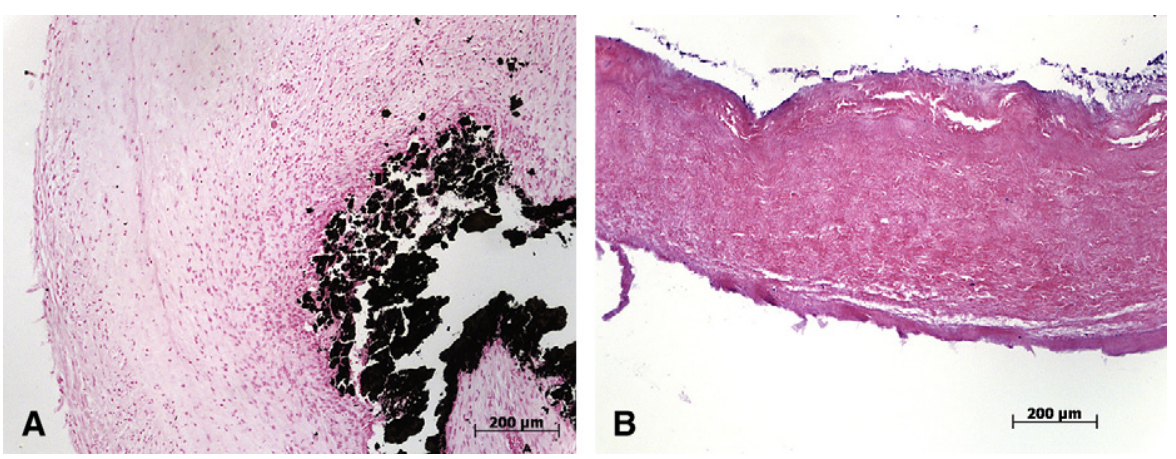

FIGURE 1. Histology of cryopreserved pulmonary valve allograft explanted at 52 weeks. A, Micrograph depicting the presence of dystrophic calcification at the base of the cusp extending into the wall of the pulmonary artery. (Original magnification $100 \times$, von Kossa stain.) B, Histologic section demonstrating the loss of cuspal cellularity after 12 months of implantation. (Original magnification $100 \times$, hematoxylin and eosin.)

potential for biologic heart valve prostheses. ${ }^{7}$ These investigators were well aware of the limitations of traditional methods, such as subcutaneous implants. A working valve in the bloodstream is in a very specific milieu. The utility and reliability of this model has consistently been reaffirmed, and thus it remains an obligatory preclinical test, as defined in the US Food and Drug Administration Replacement Heart Valve Guidance documents (US Department of Health and Human Services, 1994). This was further evidenced by our observations of valve dysfunction, calcification, or both occurring within 20 weeks for classically cryopreserved valves. In actuality, this 1 -year study confirms that the vast majority of information is learned by 20 weeks; this supports the more commonly performed 20week time interval as the standard when truly juvenile (prepubescent) sheep are used. When correlated with the explant pathology, there were no false-positive results for echocardiographic identification of calcium (Figure 4). We are not aware of any other report for a 1-year duration of implantation in which serial in vivo functional imaging studies allow comparison of 20-week and 52-week calcification data. Al- though expensive, extension of this study to 1 year was in part done to retest the sensitivity and specificity of the 20week model and once again has demonstrated its value.

Decellularization seemed to retain the advantages (eg, optimal design and excellent tissue properties) of traditional cryopreserved allografts while postponing or eliminating the quintessential marker for deterioration: calcification. Calcific failure is particularly troublesome when homografts are used in younger patients, and as such, its absence is a marker for possible prolonged durability. Prolonged durability is the rationale for and theoretic advantage of antigen reduction thorough decellularization. Lack of calcification in these studies suggests better performance but does not guarantee lifelong durability. Decellularized valves (arms 2 and 3) calcified less frequently and to a lesser extent than the traditional cryopreserved (so called viable) valves. Arm 3 test valves performed far more favorably than arm 1 valves and somewhat better than their arm 2 counterparts assessed at 20 and 52 weeks. This might be explained by some hydrolysis of the extracellular matrix during saline storage at $4^{\circ} \mathrm{C}$ (arm 2), which was obviated with glycerolization at $-80^{\circ} \mathrm{C}$
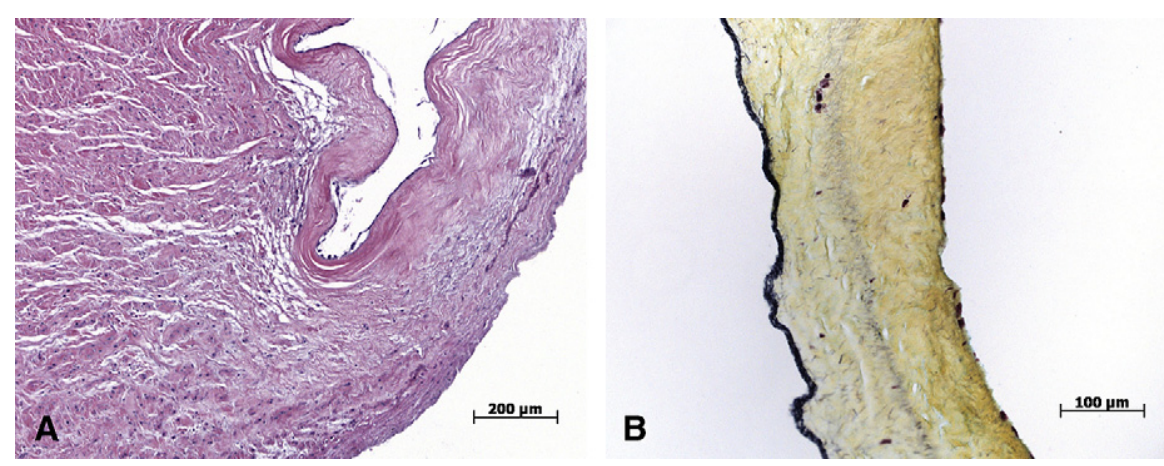

FIGURE 2. Histology of decellularized a pulmonary valve allograft explanted at 52 weeks. A, Low-magnification view depicting the recellularization of the pulmonary artery and basal region of the cusp. Pannus is seen on the luminal surface of the pulmonary artery extending onto the inflow surface of the cusp. Note the presence of focal endothelialization on the outflow surface of the cusp. (Original magnification $100 \times$, hematoxylin and eosin.) B, Higher-magnification view showing rare focal sites of recellularization of the cusp. (Original magnification $200 \times$, Movat pentachrome stain [collagens, yellow; elastic fibers, black.]) 

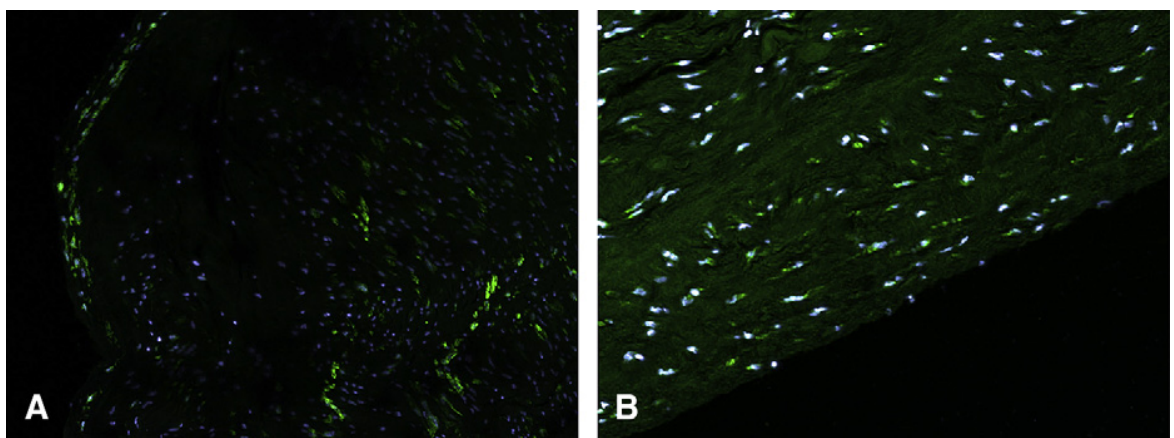

FIGURE 3. Immunohistochemistry of decellularized pulmonary valve allograft explanted at 52 weeks. A, Basal region of the cusp and pannus on the luminal surface of the pulmonary artery depicting the presence of $\alpha$-smooth muscle actin-immunoreactive cells (green). 4'-6-Diamidino-2-phenylindole dihydrochloride-stained nuclei are shown in blue. (Original magnification $100 \times$.) B, Histologic section of the pulmonary artery demonstrating the extent of recellularization by heat shock protein 47 (collagen chaperon protein with obligatory expression when cells are actively synthesizing new collagen)-immunoreactive cells in the arterial wall and within pannus on the luminal surface. Heat shock protein 47 indicates active collagen synthesis. Together, heat shock protein 47 and $\alpha$-smooth muscle actin suggest a myofibroblast phenotype consistent with valve interstitial cells. 4'-6-Diamidino-2-phenylindole dihydrochloride-stained nuclei are shown in cyan. (Original magnification $200 \times$.)

(arm 3). Alternatively, the high osmotic gradient established during glycerol treatment might have further extracted antigenic material, including cell-wall fragments, proteins, lipoproteins, and lipopolysaccharides.

Although effective in preventing or postponing conduit wall and leaflet calcifications, decellularization did not totally protect against suture line (anastomotic) calcifications (Table 3). Presumably, surgical injury to native tissue was in itself proinflammatory, occasionally provoking fibrocalcification independent of the transplanted tissue type. This indicates the sensitivity of sheep tissue to any cell injury or necrosis, typically responding with calcification of the affected tissue.

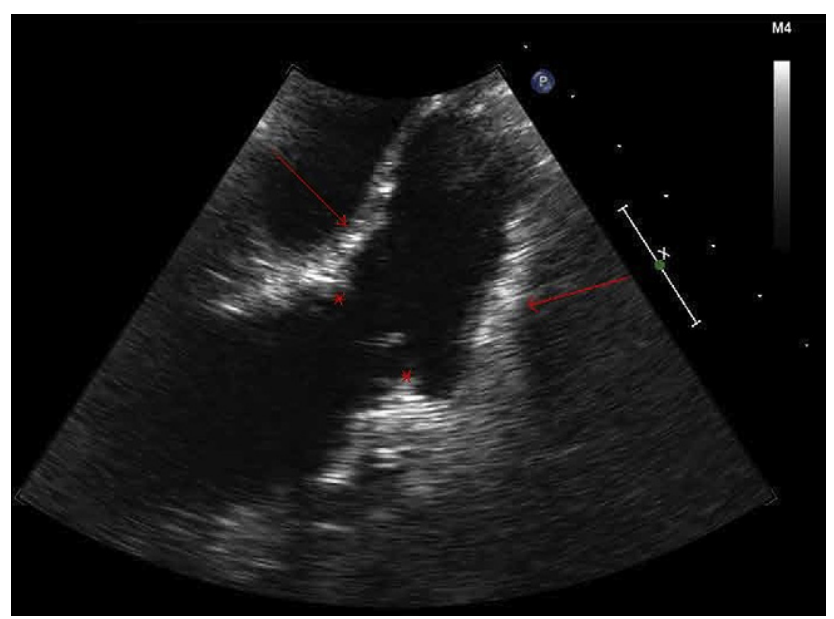

FIGURE 4. Echocardiogram of juvenile sheep. Sagittal view of right ventricular outflow tract traditional, clinically analogous, cryopreserved allograft obtained 20 weeks after implantation. Note calcium in the leaflets (circles) and conduit walls (arrows).
Previously, we have detailed a PRA assay for monitoring immune responses within the juvenile ovine cardiac valve chronic implant model. Animals were treated with antibiotics for each serum sampling during that 20 -week study. ${ }^{11}$ Antibiotics were not administered throughout this longer study to ensure the health of the animals. Without antibiotic suppression, data from the PRA assay were highly scattered and without recognizable patterns. As ruminants with 4-part stomachs, sheep contain a large bacterial/fungal load in the blood and gastrointestinal tract that maintains the animals in an almost constant low-level inflammatory state. ${ }^{14}$ Therefore this assay seems to be an unreliable tool for application in longer-term juvenile ovine studies. ${ }^{15-21}$

The explant histopathology findings exemplified in Figures 1 to 3 will be explored more quantitatively and reported separately. Qualitatively, the autologous in vivo cell in-migration into the sinus and pulmonary artery wall appears to progress with phenotypically appropriate cells. These cells might block/prevent the inflammation and scar healing responses typically seen in cryopreserved homografts or xenograft valves. ${ }^{13,16,22-27}$ However, none of the valves underwent significant leaflet recellularization beyond the cusp base (where adventitial wall cell in-migration could reach). This lack of leaflet recellularization might limit the long-term performance because lifelong durability presumably depends on leaflet valve interstitial cells actively resynthesizing structural protein for constructive and adaptive remodeling of the valve matrix.

The primary end point of this study was valve deterioration, as marked by calcifications. Conduit valve dysfunction inexorably follows as a consequence of biologic deterioration. Leaflet dysfunction is correlated with calcification. The echocardiographic, cardiac catheterization, and direct dimension measurements were internally consistent; the few hemodynamic differences were not great and did not reflect severe stenosis/regurgitation hemodynamics or the 
development of ventricular dysfunction. This is not inconsistent with clinical experience in which right ventricular outflow tract conduit deterioration can be significantly advanced before hemodynamic deterioration is manifest. In its limited application in this study, MRI did not significantly add to information acquired by means of serial echocardiographic analysis, explant pathology (including specimen radiographic analysis), and terminal cardiac catheterization with angiographic analysis. Cost and the need for an additional anesthetic episode mitigate its appeal in chronic valve performance testing. With its easier application and serial capability, 3-dimensional echocardiographic analysis might be a more appealing functional test than MRI. Transthoracic echocardiographic analysis is technically difficult once the sheep grow to greater than $150 \mathrm{lbs}$. Thus transesophageal echocardiography after light anesthesia is a more reliable method.

This experiment was designed to compare decellularized valves with the most widely used nonmanufactured clinical valve, the cryopreserved homograft, thus testing "homografts" that have been altered in biologic content rather than functional design. The central question was whether decellularization retains the advantages of traditional cryopreserved allografts while prolonging durability by reducing calcifications. This hypothesis is affirmed. The surgical, hemodynamic, and performance advantages of homograft valves seem to be preserved with the antigen-reduced decellularized valves. If, with experience, clinical durability is demonstrated, as implied by these results in juvenile sheep, then a decellularized homograft valve might truly be an improved homograft for use in the right ventricular outflow tract, although the lack of leaflet recellularization by 52 weeks is of concern as a potential long-term hazard. If safety is demonstrated with clinical use, such decellularized valves might also be candidates for use as extracellular matrix scaffolds for bioreactor-based cell-seeding strategies, creating recellularized tissue-engineered heart valves. ${ }^{6,28,29}$

We thank biostatistician Ashley K. Sherman, MS, Cardiac Surgery Research Laboratories, the Children's Mercy Hospitals and Clinics, Kansas City, Mo. We also recognize the contributions by the veterinarians and staff of Thomas D. Morris, Inc, to the successful surgeries and animal husbandry and appreciate the data organization by Dawn E. Verdugo, $\mathrm{PhD}$, which facilitated the statistical review.

\section{References}

1. Hilbert SL, Luna RE, Zhang J, et al. Allograft heart valves: the role of apoptosismediated cell loss. J Thorac Cardiovasc Surg. 1999;117:454-62.

2. Hopkins RA. Bioprosthetic valves and laudable inflammation? Circulation. 2006; 114:261-4.

3. Messier RH, Domkowski PW, Aly HM, et al. Adenine nucleotide depletion in cryopreserved human cardiac valves: the "stunned" leaflet interstitial cell population. Cryobiology. 1995;32:199-208.

4. Rhim C, Niklason LE. Tissue engineered vessels: cells to telomeres. Prog Pediatr Cardiol. 2006;21:185-91.
5. Fong P, Shin'oka T, Lopez-Soler RI, Breuer C. . The use of polymer based scaffolds in tissue-engineered heart valves. Prog Pediatr Cardiol. 2006;21:193-9.

6. Hopkins R. From cadaver harvested homograft valves to tissue-engineered valve conduits. Prog Pediatr Cardiol. 2006;21:137-52.

7. Jones M, Eidbo EE, Hilbert SL, Ferrans VJ, Clark RE. Anticalcification treatments of bioprosthetic heart valves: in vivo studies in sheep. $J$ Card Surg. 1989;4:69-73

8. Hilbert SL, Barrick MK, Ferrans VJ. Porcine aortic valve bioprostheses: a morphologic comparison of the effects of fixation pressure. J Biomed Mater Res. 1990;24:773-87.

9. Hopkins RA, Hopkins RA. Cardiac reconstructions with allograft tissues. New York: Springer-Verlag; 2005.

10. Hilbert SL, Yanagida R, Souza J, et al. Prototype anionic detergent technique used to decellularize allograft valve conduits evaluated in the right ventricular outflow tract in sheep. J Heart Valve Dis. 2004;13:831-40.

11. Ketchedjian A, Kreuger P, Lukoff $\mathrm{H}$, et al. Ovine panel reactive antibody assay of HLA responsivity to allograft bioengineered vascular scaffolds. J Thorac Cardiovasc Surg. 2005;129:159-66.

12. Haycock GB, Schwartz GJ, Wisotsky DH. Geometric method for measuring body surface area: a height-weight formula validated in infants, children, and adults. J Pediatr. 1978;93:62-6.

13. Koolbergen DR, Hazekamp MG, de Heer E, et al. The pathology of fresh and cryopreserved homograft heart valves: an analysis of forty explanted homograft valves. J Thorac Cardiovasc Surg. 2002;124:689-97.

14. Simon P, Kasimir M-T, Rieder E, Weigel G. . Tissue Engineering of heart valves-immunologic and inflammatory challenges of the allograft scaffold Prog Pediatr Cardiol. 2006;21:161-5.

15. Christenson JT, Kalangos A. Blood group antigenicity and clinical durability of cryopreserved homografts. Prog Pediatr Cardiol. 2006;21:227-31.

16. Ketchedjian A, Jones AL, Krueger P, et al. Recellularization of decellularized allograft scaffolds in ovine great vessel reconstructions. Ann Thorac Surg. 2005;79: 888-96.

17. Shaddy RE, Thompson DD, Osborne KA, Hawkins JA, Fuller TC. Persistence of human leukocyte antigen (HLA) antibodies after one year in children receiving cryopreserved valved allografts. Am J Cardiol. 1997;80:358-9.

18. Hoekstra F, Witvliet M, Knoop C, et al. Donor-specific anti-human leukocyte antigen class I antibodies after implantation of cardiac valve allografts. J Heart Lung Transplant. 1997;16:570-2.

19. Christenson JT, Vala D, Sierra J, Beghetti M, Kalangos A. Blood group incompatibility and accelerated homograft fibrocalcifications. J Thorac Cardiovasc Surg. 2004; 127:242-50.

20. Hoekstra FM, Witvliet M, Knoop CY, et al. Immunogenic human leukocyte antigen class II antigens on human cardiac valves induce specific alloantibodies. Ann Thorac Surg. 1998;66:2022-6.

21. Rajani B, Mee RB, Ratliff NB. Evidence for rejection of homograft cardiac valves in infants. J Thorac Cardiovasc Surg. 1998;115:111-7.

22. Kasimir MT, Rieder E, Seebacher G, et al. Decellularization does not eliminate thrombogenicity and inflammatory stimulation in tissue-engineered porcine heart valves. J Heart Valve Dis. 2006;15:278-86.

23. Vogt PR, Stallmach T, Niederhauser U, et al. Explanted cryopreserved allografts a morphological and immunohistochemical comparison between arterial allografts and allograft heart valves from infants and adults. Eur J Cardiothorac Surg. 1999;15:639-44.

24. Simon P, Kasimir MT, Seebacher G, et al. Early failure of the tissue engineered porcine heart valve SYNERGRAFT(TM) in pediatric patients. Eur J Cardiothorac Surg. 2003;23:1002-6.

25. De Visscher G, Blockx H, Meuris B, et al. Functional and biomechanical evaluation of a completely recellularized stentless pulmonary bioprosthesis in sheep. J Thorac Cardiovasc Surg. 2008;135:395-404.

26. Schmidt D, Stock UA, Hoerstrup SP. Tissue engineering of heart valves using decellularized xenogeneic or polymeric starter matrices. Philos Trans $R$ Soc Lond B Biol Sci. 2007;362:1505-12.

27. Taylor PM, Cass AEG, Yacoub MH. Extracellular matrix scaffolds for tissue engineering heart valves. Prog Pediatr Cardiol. 2006;21:219-25.

28. Lichtenberg A, Breymann T, Cebotari S, Haverich A. Cell seeded tissue engineered cardiac valves based on allograft and xenograft scaffolds. Prog Pediatr Cardiol. 2006;21:211-7.

29. Bechtel JF, Stierle U, Sievers HH. Fifty-two months' mean follow up of decellularized SynerGraft-treated pulmonary valve allografts. J Heart Valve Dis. 2008; 17:98-104. 


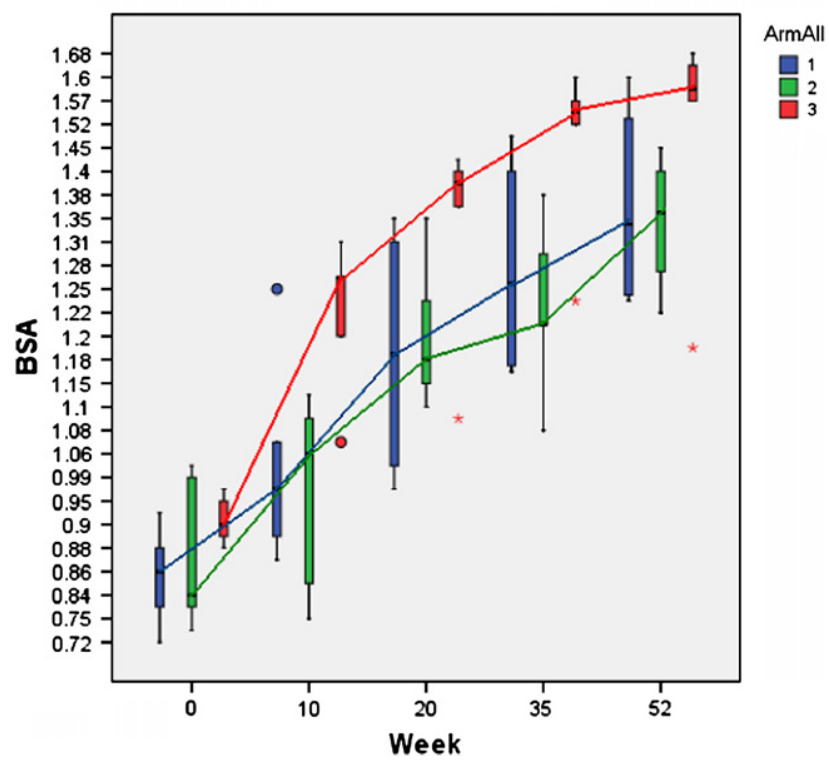

FIGURE E1. Body surface area (BSA) distribution per treatment over time for weeks 10, 20, 35, and 52. Box plots of 1 years' growth (body surface area) for each arm are shown, with individual points per treatment at weeks 10, 20, 37, and 52. Means are connected. There were no significant differences in the rates of growth among the 3 arms over time $(P=.145)$.
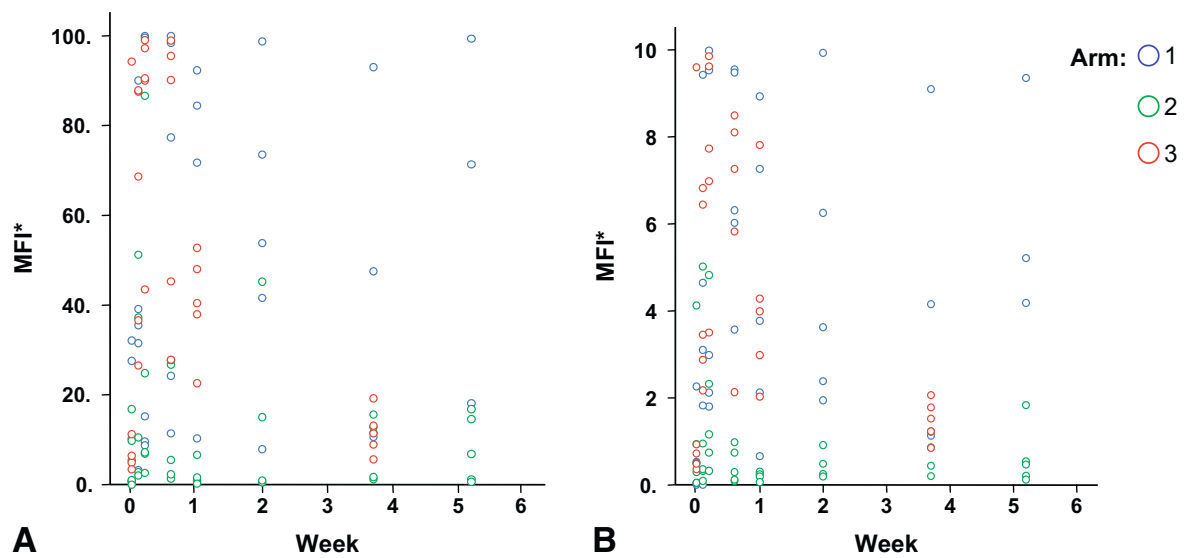

FIGURE E2. Ovine panel reactive antibody scatter plots over the 1-year study. Scatter plots of panel reactive antibody data for 3 arms over the course of 52 weeks are shown: A, major histocompatibility complex I; B, major histocompatibility complex II. The range of points could not be statistically fit. MFI, Mean fluorescence intensity. 
TABLE E1. Echocardiographic Doppler gradients

\begin{tabular}{|c|c|c|c|c|c|c|c|c|c|c|}
\hline \multirow[b]{2}{*}{ Time (wk) } & \multirow[b]{2}{*}{ No. } & \multicolumn{2}{|c|}{$\begin{array}{c}\text { Peak gradient } \\
(\mathrm{mm} \mathrm{Hg})\end{array}$} & \multicolumn{2}{|c|}{$\begin{array}{c}\text { Mean gradient } \\
(\mathrm{mm} \mathrm{Hg})\end{array}$} & \multirow[b]{2}{*}{ No. } & \multicolumn{2}{|c|}{ EOA $\left(\mathrm{cm}^{2}\right)$} & \multicolumn{2}{|c|}{ EOA/BSA } \\
\hline & & Mean & SD & Mean & SD & & Mean & SD & Mean & SD \\
\hline \multicolumn{11}{|l|}{10} \\
\hline Arm 1 & 5 & 7.12 & 6.22 & 2.82 & 1.81 & 5 & 5.78 & 2.31 & 5.64 & 1.96 \\
\hline Arm 2 & 4 & 5.45 & 1.41 & 2.08 & 0.68 & 5 & 4.54 & 1.22 & 4.89 & 2.08 \\
\hline Arm 3 & 4 & 2.60 & 0.67 & 1.50 & 0.51 & 5 & 5.90 & 0.78 & 4.87 & 0.81 \\
\hline \multicolumn{11}{|l|}{20} \\
\hline Arm 1 & 4 & 4.83 & 3.49 & 2.15 & 1.31 & 4 & 5.58 & 2.22 & 4.65 & 1.19 \\
\hline Arm 2 & 4 & 4.28 & 2.27 & 1.83 & 1.07 & 4 & 4.83 & 0.76 & 3.99 & 0.52 \\
\hline Arm 3 & 4 & 3.30 & 0.48 & 1.85 & 0.47 & 5 & 6.04 & 0.98 & 4.58 & 1.06 \\
\hline \multicolumn{11}{|l|}{37} \\
\hline Arm 1 & 4 & 4.75 & 1.85 & 2.18 & 0.97 & 4 & 6.13 & 3.14 & 4.54 & 1.90 \\
\hline Arm 2 & 4 & 4.30 & 1.89 & 2.08 & 0.94 & 4 & 5.05 & 1.15 & 4.20 & 0.75 \\
\hline Arm 3 & 5 & 3.40 & 1.69 & 1.84 & 0.77 & 5 & 6.58 & 1.11 & 4.49 & 1.21 \\
\hline \multicolumn{11}{|l|}{52} \\
\hline Arm 1 & 1 & 2.90 & * & 1.50 & * & 3 & 6.53 & 3.39 & 4.49 & 2.15 \\
\hline Arm 2 & 1 & 4.90 & * & 10.4 & * & 3 & 4.90 & 0.96 & 3.75 & 0.74 \\
\hline Arm 3 & 5 & 3.08 & 1.26 & 1.60 & 0.50 & 5 & 6.58 & 0.61 & 4.40 & 0.97 \\
\hline
\end{tabular}

No differences were detected between groups for gradients or effective orifice area measurements. $E O A$, Effective orifice area; $B S A$, body surface area; $S D$, standard deviation. $* \mathrm{~N}=$ 1 for these time points because of technical difficulties in acquiring transthoracic echocardiographic windows in the large 1-year old sheep, and therefore no standard deviation was determined.

TABLE E2. Cardiac catheterization data

\begin{tabular}{|c|c|c|c|c|c|c|c|c|c|}
\hline & $\begin{array}{l}\text { Arm } 1 \\
(n=4)\end{array}$ & $\begin{array}{l}\text { Arm } 2 \\
(n=4)\end{array}$ & $\begin{array}{l}\text { Arm 3 } \\
(\mathbf{n}=\mathbf{5})\end{array}$ & $\begin{array}{c}P \\
\text { value }\end{array}$ & & $\begin{array}{l}\text { Arm } 1 \\
(n=4)\end{array}$ & $\begin{array}{l}\text { Arm 2 } \\
(n=4)\end{array}$ & $\begin{array}{l}\text { Arm 3 } \\
(\mathbf{n}=5)\end{array}$ & $\begin{array}{c}P \\
\text { value }\end{array}$ \\
\hline Cardiac output (mL/min) & & & & & $\begin{array}{l}\mathrm{RV} \text { mean pressure } \\
(\mathrm{mm} \mathrm{Hg})\end{array}$ & & & & \\
\hline Mean & 5750 & 5100 & 4680 & & Mean & 12.75 & 9.25 & 18.2 & \\
\hline SD & 2007 & 2986 & 756 & .740 & SD & 2.75 & 1.71 & 2.95 & .001 \\
\hline $\begin{array}{l}\text { Cardiac index } \\
\qquad\left(\mathrm{L} \cdot \mathrm{min}^{-1} \cdot \mathrm{m}^{-2}\right)\end{array}$ & & & & & $\begin{array}{l}\text { PA pressure, systolic } \\
(\mathrm{mm} \mathrm{Hg})\end{array}$ & & & & \\
\hline Mean & 4.88 & 4.18 & 3.62 & & Mean & 21.0 & 14.8 & 28.2 & \\
\hline SD & 1.67 & 2.36 & 0.79 & .548 & SD & 5.10 & 5.12 & 6.87 & .021 \\
\hline Gorlin EOA $\left(\mathrm{cm}^{2}\right)$ & & & & & $\begin{array}{l}\text { PA pressure, mean } \\
(\mathrm{mm} \mathrm{Hg})\end{array}$ & & & & \\
\hline Mean & 2.16 & 2.56 & 1.76 & & Mean & 13.0 & 9.25 & 19.6 & \\
\hline $\mathrm{SD}$ & 0.75 & 2.05 & 0.29 & .626 & SD & 2.58 & 1.26 & 3.78 & .001 \\
\hline $\begin{array}{l}\text { EOA index } \\
\qquad\left(\text { EOA/BSA; } \mathrm{cm}^{2} / \mathrm{m}^{2}\right)\end{array}$ & & & & & $\begin{array}{l}\text { PA pressure, diastolic } \\
(\mathrm{mm} \mathrm{Hg})\end{array}$ & & & & \\
\hline Mean & 1.54 & 1.84 & 1.17 & & Mean & 7.25 & 4.50 & 11.60 & \\
\hline SD & 0.39 & 1.44 & 0.28 & .507 & SD & 0.96 & 1.91 & 2.88 & .002 \\
\hline $\mathrm{RV}$, systolic (mm Hg) & & & & & $\begin{array}{l}\text { Mean transvalvular } \\
\text { gradient }(\mathrm{mm} \mathrm{Hg})\end{array}$ & & & & \\
\hline Mean & 21.5 & 14.25 & 27.0 & & Mean & 0.00 & 0.25 & 0.80 & \\
\hline SD & 5.26 & 5.91 & 5.15 & .018 & SD & 0.00 & 0.50 & 0.45 & .032 \\
\hline $\mathrm{RV}$, diastolic $(\mathrm{mm} \mathrm{Hg})$ & & & & & $\begin{array}{l}\text { Peak transvalvular } \\
\text { gradient }(\mathrm{mm} \mathrm{Hg})\end{array}$ & & & & \\
\hline Mean & 6.25 & 5.00 & 11.2 & & Mean & 0.75 & 0.50 & 3.20 & \\
\hline SD & 2.06 & 1.63 & 3.03 & .007 & SD & 1.50 & 0.58 & 2.86 & .129 \\
\hline
\end{tabular}

$P$ values are listed for any arm differences for each given parameter. Tukey post-hoc comparisons were subsequently applied to determine where differences occurred. Differences tended to be biologically benign (eg, although mean transvalvular gradients were statistically different, the range was $0.0-0.8 \mathrm{~mm} \mathrm{Hg}$ across the arms). $S D$, Standard deviation; $R V$, right ventricular; $P A$, pulmonary artery; $E O A$, effective orifice area; $B S A$, body surface area. 
TABLE E3. Directly measured implant versus explant valve conduit dimensions

\begin{tabular}{lccrc}
\hline \multicolumn{1}{c}{ Variable } & Arm & Mean $(\mathbf{m m})$ & SD & No. \\
\hline Implant native & 1 & 17.0 & 1.6 & 5 \\
main PA diameter ED & 2 & 17.6 & 1.1 & 5 \\
& 3 & 16.8 & 0.4 & 5 \\
Implanted graft length & 1 & 26.4 & 1.1 & 5 \\
& 2 & 25.0 & 1.6 & 5 \\
Explant conduit length & 3 & 23.8 & 0.8 & 5 \\
& 1 & 26.9 & 11.7 & 3 \\
Implant proximal & 2 & 27.9 & 3.5 & 4 \\
anastomosis diameter & 3 & 30.3 & 6.1 & 4 \\
& 1 & 21.5 & 2.1 & 5 \\
Explant proximal & 3 & 22.2 & 2.6 & 5 \\
anastomosis diameter & 1 & 22.6 & 1.5 & 5 \\
& 2 & 21.4 & 3.5 & 4 \\
Implant distal & 3 & 22.0 & 18.1 & 4 \\
anastomosis diameter & 1 & 21.4 & 1.9 & 5 \\
& 2 & 21.8 & 2.5 & 5 \\
Explant distal & 3 & 23.0 & 2.8 & 5 \\
anastomosis diameter & 1 & 30.8 & 13.5 & 4 \\
& 2 & 54.5 & 3.1 & 4 \\
\hline Ong & 3 & 21.7 & 1.2 & 5 \\
\hline
\end{tabular}

One outlier in arm 2 resulted from an animal that had leaflet dysfunction from subvalvular distortion at the suture line. Accordingly, the distal asymmetric enlargement (including the sinotubular junction, distal anastomosis, and distal native pulmonary artery) was due to jetting and not growth or diffuse aneurysmal dilation. Taking this finding into account, by means of univariate testing, including the $\mathrm{F}$ test for 1-way generalized linear models comparing means for arm 1 with arm 3, there were no differences in the directly measured implant pulmonary artery diameters, proximal and distal anastomosis diameters, and the explant conduit length measurements. $S D$, Standard deviation; $P A$, pulmonary artery; $E D$, end diastolic.

\section{Appendix E1. Valve decellularization methodology.}

Valve conduits were treated with an anionic nondenaturing detergent (N-lauroyl sarcosinate; Sigma, St Louis, Mo) in a Tris buffer solution (recirculated at room temperature for 24 hours) containing a recombinant endonuclease (Benzonase; EMD BioSciences, Gibbstown, NJ), lincomycin, polymyxin $\mathrm{B}$, and vancomycin. After detergent and endonuclease treatment, the valve conduits were rinsed (at room temperature) by recirculating water through a bed of anion exchange resin and hydrophobic adsorbent resin for 24 hours. The valves were either removed from the decellularization chamber and placed into isotonic saline with polymyxin B or underwent glycerolization for 24 hours (LifeNet Health; US Patents 6,743,574 and 6,432,712). After processing, storage was at less than $-110^{\circ} \mathrm{C}$ for the standard cryopreserved valves, $1^{\circ} \mathrm{C}$ to $10^{\circ} \mathrm{C}$ for the decellularized saline-stored valves, and $-80^{\circ} \mathrm{C}$ for the decellularized glycerolized valves.

\section{Appendix E2. Ovine echocardiographic protocol}

A short-axis view of the base of the heart near the level of the right ventricular outflow tract and implanted valve was used for initial orientation. Internal diameters of the proximal distal anastomosis, as well as the valve annulus, were measured during systole by means of 2-dimensional echocardiographic analysis. The presence and severity of regurgitation through the implanted test valve was evaluated by means of color flow Doppler imaging. Severity of regurgitation was classified as follows: trace (1+), regurgitant jet is limited to the immediate valve area; mild (2+), jet limited to the right ventricular outflow tract; moderate $(3+)$, jet extending into the right ventricular cavity; and severe (4+), jet extended to the tricuspid valve. The peak pressure gradient across the implanted valve was measured by means of continuous-wave Doppler imaging. A parastenal short-axis view of the left ventricle at the midpapillary muscle level was obtained to measure ejection fraction, and stroke volume was obtained by using the Teicholz method. The EOA was determined by using a modified continuity equation, assuming that stroke volume was equal in the right and left ventricles so that EOA is defined as left ventricular stroke volume divided by volume thickness index. All echocardiographic images were obtained by one operator and reviewed by a second operator for accuracy. Valves were also qualitatively evaluated for apparent thickness of the leaflets, stiffness of the leaflets, and presence or absence of calcifications in the leaflets or conduit wall.

\section{Appendix E3. Ovine PRA protocol}

Serum was run through a HiTrap purification system (Amersham Biosciences, Buckinghamshire, United Kingdom). Purified serum was incubated with beads (One Lambda, Inc, Canoga Park, Calif) tagged with 30 major histocompatibility complex I and 30 major histocompatibility complex II HLA antigens for 30 minutes in the dark with continuous gentle shaking. The beads were washed with buffer solution and centrifuged at 11,500 rpm for 2 minutes. The supernatant was removed, and the beads were incubated with a rabbit antisheep fluorescein isothiocyanate-labeled antibody (Jackson Immuno-Research, West Grove, Pa) for 30 minutes in the dark with continuous shaking. The beads were washed with buffer solution and centrifuged at 11,500 rpm for 2 minutes. The supernatant was removed, and the beads were fixed at $0.5 \%$ paraformaldehyde and analyzed on a Becton Dickinson FACS flow cytometer (Becton Dickinson, Franklin Lakes, NJ). Human positive and negative controls were used for calibration. FL1 histograms were obtained for all specimens. Results are reported as the percentage of beads fluorescing, and positive responses were defined based on recommended ranges by One Lambda, as in clinical use.

Appendix E4. Ovine cardiac catheterization assessment of valve EOA protocol

With fluoroscopic guidance (EOC $9600 \mathrm{C}$-Arm, vascular package) and with the sheep under light sedation, an $8 \mathrm{~F}$ 
Swan-Ganz catheter was inserted through the left jugular vain and correctly positioned with the tip in the distal main pulmonary artery.

Thermodilution cardiac outputs were obtained in triplicate on 3 separate occasions, averaged, and normalized to body surface area by using the Haycock formula. The SwanGanz catheter was exchanged for a single hole-tipped catheter, and 3 pullback pressure gradients were obtained across the test valve. EOA values were calculated with the classical Gorlin equation and indexed to body surface area values. ${ }^{12}$

\section{Appendix E5. Ovine angiographic protocol}

After pressures were measured, angiographic analysis was performed to record images of the functioning valve. Power injections (BV Pulsera; Phillips, Andover, Mass) of contrast $(75-99 \mathrm{~mL}$ total at $25-33 \mathrm{~mL} / \mathrm{s}$ with 1 -second increase) were made in the outflow portion of the right ventricle below the valve conduits to assess stenosis, leaflet motion, and ventricular function, and second injections were made in the main pulmonary artery above the test valves to assess regurgitation.

\section{Appendix E6. Ovine MRI protocol}

A long-axis cine image with steady-state free precession MRI was obtained, including 2-chamber, 4-chamber, 3chamber, and coronary obliques, by using a 1.5-Tesla Magnet (General Electric, Sigma Horizon LX, Milwaukee, Wis). A short-axis cine image from the base to the apex was obtained for volume and ejection fraction calculations. The velocity encoding gradient was set to $120 \mathrm{~cm} / \mathrm{s}$. For pulmonary valve imaging, cine steady-state free precession was positioned off axial scouts in the sagittal and oblique planes through the main pulmonary artery. The second cine plane was perpendicular to the first plane through the test valve. A phase contrast was obtained through the plane at the pulmonary valve by positioning perpendicular to the previous plane. The velocity-encoding gradient was reset to approximately $110 \mathrm{~cm} / \mathrm{s}$, as necessary. 